\title{
Nocifensive reflex thresh- olds in rats: measures of central nervous system effects of barbiturates
}

\author{
David P. Archer MD FRCPC, * \\ Naaznin Samanani BSc, ${ }^{*}$ \\ Sheldon H. Roth $\mathrm{PhD}^{\star \dagger}$
}

Purpose: To characterize the pharmacodynamic relationships between plasma pentobarbitone and thiopentone concentrations and nocifensive reflexes during emergence from anaesthesia.

Methods: Forty-nine rats were studied. Plasma barbiturate concentrations were measured with high performance liquid chromatography. Nocifensive reflexes were assessed with the hindlimb withdrawal latency $(W L)$ to heat and the somatic motor response threshold (SMRT) to tail pressure. In Protocol I, SMRT. WL, sedation, and the presence of paw-licking and the righting reflex were assessed in unrestrained rats before and every 10 min for two hours after an intraperitoneal injection of pentobarbitone $\left(30 \mathrm{mg} \cdot \mathrm{kg}^{~}\right)$. Plasma pentobarbitone kinetics were determined in a separate group of rats. In Protocol II, SMRT and drug concentrations were measured concurrently in partially restrained animals before and for 35 min after a computer-controlled $i v$ bolus of thiopentone. In Protocol III the SMRT-plasma thiopentone relationship was determined duning increasing and decreasing plasma thiopentone concentrations.

Results: Enhancement of both nocifensive reflexes was observed in the unrestrained animals. Enhancement of SMRT was maximal [175\% (153-197) of control values] at a mean plasma thiopentone concentration of II (9-13) $\mu \mathrm{g} \cdot \mathrm{ml}$ The SMRT-plasma thiopentone curve showed a mean efflux-influx difference in plasma thiopentone concentration of $4(2.3-5.7) \mu \mathrm{g} \cdot \mathrm{ml}^{-1}$.

Conclusion: Barbiturate-associated nocifensive reflex enhancement occurs in unrestraned animals with both thermal and pressure stimuli. The SMRT- plasma thiopentone concentration relationship during emergence from anaesthesia was similar to that observed previously during induction. The thiopentone plasma concentration-SMRT plot showed an equilibration delay similar to that previously described by others for thiopentone at an electroencephalographic effect site.

Objectif : Préciser les relations pharmacodynamiques entre les concentrations de pentobarbitone et de thiopentone et les réflexes nocifs de défense pendant le réveil anesthésique.

Méthodes : Quarante-neuf rats ont été étudiés. Les concentrations plasmatiques de barbituriques ont été mesurées par chromatographie liquide à haute performance. Les réflexes nocifs de défense ont été évalués par la latence du retrait (LR) du membre postérieur provoqué par la chaleur et par le seuil de réponse motnce somatique (SRMS) au serrement de la queue. Dans le protocole I, le SRMS. la LR, le degré de sédation et l'existence du léchage de la patte et du réflexe de redressement ont été recherchés sur des rats sans contention avant et aux dix min pendant deux heures après une injection intrapéritoméale de pentobarbitone (30 $\mathrm{mg} \cdot \mathrm{kg}$ '). La cinétique plasmatique du pentobarbitone a été déterminée chez un groupe séparé de rats. Dans le protocole II, le SRMS et les concentratıons de thiopentone ont été mesurés simultanément chez des rats sous contention partielle avant et 35 min après l'administration contrôlée par ordinateur d'un bolus de thiopentone. Dans le protocole III, la relation entre le SRMS et la concentration de thiopentone a été déterminée au moment de la croissance et la décroissance plasmatique du thiopentone.

Résultats : On a observé une facilitation des deux réflexes nocifs de défense chez les rats sans contention. La facilitation du SRMS était maximale [175\% (153-197) des valeurs initiales] à la concentration plasmatique moyenne de thiopentone de $1 \mid(9-13) \mu \cdot \mathrm{ml}$. La courbe SRMS/thiopentone a révélé une différence efflux-influx de la concentration plasmatique de thiopentone de $4(2,3-5,7) \mathrm{g} \cdot \mathrm{ml}^{-1}$.

Conclusion : Une facilitation du réflexe nocif de défense associée aux barbituriques survient chez des rats sans contention stimulés par la chaleur ou la compression. La relation entre le SRMS et la concentration plasmatique du thiopentone pendant le réveil anesthésique est identique à celle qui a déjà été observée à l'induction. Le graphıque concentration-SRMS montre un délai d'équilibration identique a celui déjà décrit par d'autres pour le thiopentone au niveau d'un site effecteur électroencéphalographique.

From the Departments of Anaesthesia * and Pharmacology and Therapeutics, ${ }^{\dagger}$ University of Calgary, Calgary, Canada. Address correspondence to: Dr. D.P. Archer, Department of Anacsthesia, Foothills Hospital, 1403-29 Street NW, Calgary, AB Canada T2N 2T9. Phone: (403) 670-1991; Fax: (403) 670-2425; E-mail: archerd@cadvision.com

Accepted for publication April 20, 1997. 
$\mathrm{R}$ ECENT studies from our laboratory ${ }^{1-4}$ have described the relationships between withdrawal responses to noxious stimulation (nocifensive reflexes) and plasma concentrations of a variety of anaesthetics. The influence of anaesthetics on nocifensive reflexes is biphasic; at subhypnotic concentrations nocifensive reflex thresholds are reduced below control values. After loss of consciousness is achieved, thresholds increase progressively until, finally, the animal is unresponsive to the noxious stimulus. Ebling and colleagues ${ }^{5}$ have proposed characteristics of a measure of drug action in the central nervous system (CNS) which would be advantageous for pharmacodynamic research. A useful measure of drug action would 1) evaluate a direct effect of the drug on the CNS: 2) be continuous rather than quantal: 3 ) demonstrate a graded response to drug dose or concentration. ${ }^{5}$ Nocifensive reflexes are a direct measure of the CNS response to noxious stimulation that are altered in a graded, concentration-dependent manner ${ }^{1-4}$ which remains constant during clamping of plasma drug concentrations. ${ }^{2,6}$ To be useful for separating the pharmacokinetic effects of anaesthetics from their pharmacodynamic effects, it is also necessary that the alterations in nocifensive reflexes be time independent. ${ }^{5} \mathrm{~A}$ corollary of this requirement is that reflex enhancement should occur similarly during influx and efflux of the drug from the effect site. Clinically, this corresponds to induction of and emergence from anaesthesia. To complement our previous investigations performed during induction, the three protocols in this report were designed to examine nocifensive reflex thresholds during emergence from anaesthesia.

In the present studies we also wished to confirm our previous observations ${ }^{1}$ that the nociceptive effects of anaesthetics were independent of the influence of partial restraint used in our experimental model to allow acute vascular cannulation for blood sampling, because certain forms of immobilization have been used to produce stress-induced analgesia in the rat. ${ }^{8}$ Specifically, we wanted to test the hypothesis that the reflex enhancement observed previously ${ }^{1-4}$ during induction of anaesthesia was due to reversal of stressrelated analgesia. In Protocol I (Pentobarbitone Emergence) we tested this hypothesis by measuring nocifensive reflexes during emergence from pentobarbitone anaesthesia in unrestrained animals. In this group we also compared thermal with mechanical noxious stimulation, because the mechanisms of descending modulation of the reflex pathways are thought to be different for these two forms of stimuli. ${ }^{9}$

We studied pentobarbitone because it is commonly used for "light" anaesthesia in animals on the erroneous assumption that these conditions have a minimal influence on nocifensive responses. ${ }^{10}$ Thiopentone was chosen because of its common use in clinical anaesthetic practice, the extensive literature characterizing the pharmacokinetic and pharmacodynamic behaviour of this drug in rats, ${ }^{5,11-13}$ and the pharmacokinetic profile of the drug (entrance of thiopentone into brain is limited only by blood flow). ${ }^{14}$

\section{Methods}

These studies were approved by the Animal Care Committee of the Faculty of Medicine, University of Calgary and comply with the Ethical Guidelines of the International Association for the Study of Pain and the Canadian Council of Animal Care. Male SpragueDawley rats $(300-500 \mathrm{~g}$, Charles River) were housed in the medical vivarium (light on 0600-1800) with free access to food and water for at least one week before testing. Testing was performed between 10:00 and 15:00 hr. Three drug administration protocols were used (Table I).

\section{Protocol I - Pentobarbitone Emergence}

A total of 29 rats were used to evaluate behavioural responses to noxious and non-noxious stimuli during recovery from an injection of pentobarbitone anaesthesia $\left(30 \mathrm{mg} \cdot \mathrm{kg}^{-1}, i p\right)$. The study group was 11 unrestrained rats without vascular catheters. Measurements of nocifensive reflexes and behaviour were made before and every $10 \mathrm{~min}$ after drug administration for 12 intervals (total study length $120 \mathrm{~min}$ ). Eight unrestrained rats injected with an equivalent volume of saline ip subjected to the same behavioural assessments served as controls.

The dose of pentobarbitone, dissolved in $1 \mathrm{ml}$ normal saline, produced unconsciousness within twothree minutes of injection followed by gradual emergence to an alert state over the following 30-40 min. We determined the plasma pentobarbitone kinetics in a separate group of 10 partially restrained animals injected with pentobarbitone $30 \mathrm{mg} \cdot \mathrm{kg}^{-1}$ ip Arterial samples for pentobarbitone assay were drawn from these animals at times that corresponded to the periods of the behavioural measurements in the unrestrained rats.

\section{Protocol II - Thiopentone Emergence}

For this protocol, 14 rats were instrumented with arterial and venous catheters as previously described ${ }^{1,2,4}$ and outlined briefly below. The study group was seven rats that received thiopentone from a computer-controlled infusion pump programmed (STANPUMP program, courtesy of Dr. S Shafer, Stanford University, Palo Alto, CA, USA) set to achieve a target effect site concentra- 
TABLE I Drug Administration Protocols

\begin{tabular}{|c|c|c|c|}
\hline Protocol & Total Number & Drug Administration Strategy & Drug Sampling \\
\hline \multicolumn{4}{|l|}{ I Pentobarbitone } \\
\hline Emergence & 29 & $\begin{array}{l}\text { Intraperitoneal pentobarbitone, } \\
30 \mathrm{mg} \cdot \mathrm{kg}^{-1}(11 \text { rats). Study during } \\
\text { recovery. Saline injected controls } \\
\text { ( } 8 \text { rats). }\end{array}$ & $\begin{array}{l}\text { Timed sampling } \\
\text { during recovery in a } \\
\text { separate group of } 10 \\
\text { Instrumented rats. }\end{array}$ \\
\hline \multicolumn{4}{|r|}{ e } \\
\hline \multicolumn{4}{|l|}{ Thiopentone } \\
\hline Emergence & 14 & $\begin{array}{l}\text { Pseudosteady state thiopentone } \\
\text { concentration established by } \\
\text { computer-controlled infusion. } \\
\text { Study during recovery ( } 7 \text { rats). } \\
\text { Saline injected controls ( } 7 \text { rats) }\end{array}$ & $\begin{array}{l}\text { Timed sampling during } \\
\text { recovery in the } 7 \\
\text { thiopentone injected } \\
\text { animals. }\end{array}$ \\
\hline \multicolumn{4}{|c|}{ ( } \\
\hline \multicolumn{4}{|l|}{ Thiopentone } \\
\hline Influx-Efflux & 6 & $\begin{array}{l}\text { Continuous infusion of thiopentone, } \\
0.67 \mathrm{mg} \cdot \mathrm{kg}^{-1} \cdot \mathrm{min}^{-1} \text { for } 12 \mathrm{~min} \text {. } \\
\text { Studies continued for } 50 \mathrm{~min} \\
\text { after infusion terminated. Each } \\
\text { animal serves as own control. }\end{array}$ & $\begin{array}{l}\text { Timed sampling } \\
\text { during induction and } \\
\text { recovery in each of } \\
\text { the } 6 \text { animals. }\end{array}$ \\
\hline
\end{tabular}

tion of $20 \mu \mathrm{g} \cdot \mathrm{ml}^{-1} .{ }^{13}$ Once the computer estimated that the effect site had equilibrated with the plasma at the target concentration, the infusion was terminated. Physiological variables (haematocrit, rectal temperature, blood pressure, arterial blood gas tensions) were measured before and after the thiopentone infusion. Outcome variables (SMRT, plasma thiopentone concentration) were measured before and $5,7,10,15,20$, 25,30 and $35 \mathrm{~min}$ after the termination of the infusion. A separate group of seven rats injected with saline served as controls.

\section{Protocol III - Thiopentone Influx-Efflux}

In this protocol, we measured nocifensive reflex thresholds in six partially restrained rats during a 12 min continuous infusion of thiopentone, and during the subsequent redistribution and elimination of the drug (influx and efflux). The purpose of Protocol III was to determine the delay in equilibration between the plasma and the effect site for the nociceptive effects of thiopentone. Measurements of plasma thiopentone concentration and reflex threshold were made during influx (before and at $2,4,8$, and $12 \mathrm{~min}$ after the beginning of the infusion) and efflux $(2,4,8,12,16,20$ and $50 \mathrm{~min}$ after the infusion was stopped) of thiopentone. Arterial blood gas tensions were measured before and after 12 min of infusion.

\section{Measures of nocifensive reflexes}

In the unrestrained animals in Protocol I (11 pentobarbitone-treated, eight saline controls) we assessed thermal nociception with the radiant heat technique first described by Hargreaves et al. ${ }^{15}$ The animal is placed in an acrylic chamber $(19 \mathrm{~cm} \times 28 \mathrm{~cm} \times 29 \mathrm{~cm})$ that is suspended $10 \mathrm{~cm}$ above the table top and fitted with a glass floor. The radiant heat source is a projector lamp bulb (Radius $\circledast$ tungsten halogen lamp, General Electric model EJY, 19 volts, 80 watts) installed in a movable lamp housing $40 \mathrm{~mm}$ below the glass floor and projecting through a $5 \mathrm{~mm} \times 10 \mathrm{~mm}$ aperture in the covering of the housing. The electronic circuit consists of a switch, lamp, photocell and electronic timer. The photocell is located within the lamp housing and is aimed at the aperture. After the animal has acclimatized to the chamber and is resting quietly, the aperture is positioned beneath the left hindpaw. When the switch is closed, the lamp and the electronic timer are activated until the first movement of the paw opens the circuit. Using this device, the withdrawal latency can be determined automatically to the nearest $0.1 \mathrm{sec}$. Withdrawal latency was measured with a single trial at each time in the protocol. ${ }^{15}$

Somatic motor response to tail pressure(SMRT) was measured using an Analgesy-Meter (Ugo Basile, Stoelting Instruments, Chicago, Ill., USA) as previously described. ${ }^{2}$ The partial restraint commonly used with the Randall Selitto technique was avoided by gently covering the unrestrained rat (Protocol I - Pentobarbitone Emergence) with a small towel. After two to three minutes, the rat acclimatized to this environment, and the tail was gently withdrawn from beneath the cloth and placed on the plinth of the Analgesy-Meter ${ }^{\circledR}$. The individual determining the endpoint was blinded to the reading on the scale of the device. The SMRT was calculated as the average of three trials at each measurement time. In Protocols II and III, SMRT was measured in the same fashion except that the animals were partially restrained with hindlimb restraint as described above. 
Paw-licking, sedation, and righting reflex assessment

At the time of each measurement of nocifensive reflexes, the unrestrained rats (Protocol I) were assessed for three measures of behaviour: level of sedation, the presence of paw licking in response to the thermal stimulus, and the presence or absence of the righting reflex. The righting reflex was judged to be present if, within one minute of being placed supine, the rat made any attempt to turn into the prone position. The level of sedation was defined by a score: 0 - alert, actively exploring the environment, 1 - drowsy, responds readily to light stimulation of the face or vibrissae, 2 - very drowsy, responds to vigorous stimulation of the face or the vibrissae, 3 unresponsive to facial or vibrissal stimulation. Partially restrained rats (Protocols II and III) were only assessed for SMRT.

\section{Drug assay and data analysis}

Plasma sampling and intravenous thiopentone administration were facilitated with arterial and venous cannulation respectively. ${ }^{7}$ Under general anaesthesia with halothane $2-3 \%$ in oxygen, $1 \mathrm{~cm}$ lengths of polyethlyene tubing (inside diameter $0.58 \mathrm{~mm}$ ) were inserted into the femoral artery and vein. A plaster cast was applied from the ankles to the mid-abdomen to provide hindlimb restraint and the animals were observed for two hours under a warming light to eliminate the halothane. ${ }^{3}$ Plasma concentrations of barbiturate were measured by high performance liquid chromatography (HPLC) as previously described ${ }^{1,2}$ Shed blood was replaced with normal saline in a ratio of three volumes saline: one volume blood. Cannulae were also inserted into all of the animals in Protocols II and III.

For the pentobarbitone assay, the limit of detection was $1 \mu \mathrm{g} \cdot \mathrm{ml}^{-1}$, the accuracy $\pm 3 \%$ and the coefficient of variation $\pm 3.5 \%$. For thiopentone, the limit of detection was $0.3 \mu \mathrm{g} \cdot \mathrm{ml}^{-1}$, the accuracy $\pm 4.5 \%$ and the coefficient of variation $\pm 5 \%$.

Parametric variables were characterized by mean values $\pm 95 \%$ confidence intervals $(\mathrm{CI})$. The measurements of nocifensive reflexes were normalized by expressing the value obtained at each measurement time as a percent of the pre-injection measurement in that animal. The means and standard errors for these percentages of control measurements were calculated for the study groups receiving either drug or saline and compared by two way repeated measures ANOVA. Differences between drug-treated and control groups at specific measurement times were isolated with the Student Newman Keuls test. We fitted relationships to the pharmacodynamic data (nocifensive effect $v$ s plasma barbiturate concentration) by progressive polynomial regression analysis from zero to third order. The "best fit" was selected as the lowest order polyno- mial that produced a marked improvement in predictive ability, as judged from the incremental $F$ value. The incremental $F$ value was calculated as: $F=$ incremental variation from the dependent variable mean/residual variation about the regression curve. Statistical significance was inferred when $P<0.05$. Staristical analyses, curve fitting and graphics were performed using SigmaStat ${ }^{\mathrm{TM}}$ and SigmaPlot ${ }^{\mathrm{TM}}$ software (Jandel Scientific, San Rafael, CA, USA).

In Protocol II - Thiopentone Emergence, the pharmacodynamic descriptors of the relationship between SMRT and plasma thiopentone concentrations were derived as described by Stanski. ${ }^{16}$ To facilitate comparison with previously published models of anaesthetic EEG effects, we transformed the normalized SMRT data with the function $(1 /$ SMRT $\times 100)$ to yield a function that would indicate increased responsiveness at low thiopentone concentrations, followed by inhibition of the nocifensive response. The activated portion of the drug concentration-response curve for each individual animal was described by the maximum observed (percentage of transformed SMRT control value) and the corresponding plasma thiopentone concentration $\left(C \mathrm{p}_{\max }\right)$. Mean values and $95 \% \mathrm{CI}$ for the maxima and the $\mathrm{Cp}_{\max }$ were calculated. From data obtained from previous studies in our laboratory, ${ }^{1,2,4}$ we identified a group of animals studied under a similar range of thiopentone concentrations. However, these latter results were obtained during induction of anaesthesia with thiopentone. Approximately $78 \%$ of these animals demonstrated maxima in their transformed SMRT values (Table III). These maxima and $\mathrm{CP}_{\max }$ data were analyzed to provide a comparison of the activation curve during induction ${ }^{1,2,4}$ with the results obtained during emergence (present study).

Results from Protocol III - Thiopentone InfluxEfflux were analyzed as described by Hull et al. ${ }^{17}$ and Fuseau and Sheiner. ${ }^{18}$ Over the full range of anaesthetic concentrations, the nocifensive effect - plasma thiopentone plot is biphasic ${ }^{2}$ and therefore unsuitable for analysis by the constant effect method of Hull. ${ }^{17}$ However, within the limited range of plasma concentrations used $\left(0-20 \mu \mathrm{g} \cdot \mathrm{ml}^{-1}\right)$, the nocifensive effect plasma thiopentone concentration relationship is linear, ${ }^{2,4}$ (see also Figure 4B), and therefore monotonic, allowing analysis at constant effect. Accordingly, we selected discrete values of nocifensive effect on the influx and efflux limbs of the CNS effect-plasma thiopentone concentration plot (Figure 5). For each value of nocifensive effect the equilibration error was calculated as one half of the difference between the plasma thiopentone concentration on the influx limb and the corresponding thiopentone concentration on 
the efflux limb of the plot. This strategy is similar to the technique used by Fuseau and Sheiner ${ }^{18}$ to derive the pharmacokinetic parameters of the effect site by superposition of the influx and efflux limbs of the effect-concentration curve. From these data we calculated the mean equilibration error and $95 \%$ confidence interval.

\section{Results}

Pharmacokinetic profiles and physiological effects

The plasma barbiturate concentrations during each of the three protocols are shown in Figure $\mathrm{A}$ and $\mathrm{IB}$ and Figure 5A. The computer controlled infusion program predicted equilibrium between plasma and the "CNS effect site" two minutes after the initial bolus and infusion. Approximately $24 \mathrm{mg} \cdot \mathrm{kg}^{-1}$ thiopentone were given with this strategy. The measured peak plasma thiopentone concentration was consistantly less than the target concentration of $20 \mu \mathrm{g} \cdot \mathrm{ml}^{-1}$ (Figure 1B).

For all three protocols, values of arterial blood gas tension, hacmatocrit, rectal temperature and mean arterial pressure remained within normal limits for our laboratory values for awake rats.

\section{Protocol I - Pentobarbitone emergence}

The behavioural effects of pentobarbitone are summarized in Table II. Rats were unresponsive to non-noxious stimulation of the vibrissae and face (sedation score 3 ) within two minutes after the injection, and the majority $(7 / 11)$ lost their righting reflex. Before the pentobarbitone injection, six rats demonstrated paw licking in response to the radiant heat stimulus. This behaviour disappeared with the drug injection and was not observed again (in $4 / 11$ animals) until the animals were awake or only lightly sedated (sedation scores 0-1). Behaviour did not change in the saline injected animals.

\section{Nocifensive reflexes}

In the saline-treated rats there was a small, but significant decrease in withdrawal latency with repeated testing (Figure 2). When subjected to regression analysis, the withdrawal latency was shown to decrease $0.17 \%$ per minute $(P=0.018)$ for a total decrease during the experiment from $13.3(9.9-16.7) \mathrm{sec}$ (control) to 10.5 (7.3-13.9) $\mathrm{sec}(120 \mathrm{~min})$.

After pentobarbitone injection, WL rapidly decreased from 15.6 (14.1-17.I) sec (control) to a minimum of 9.1 (7.6-10.6) sec $(P<0.001$, Figure 2A). The nadir of the withdrawal latency was observed $40 \mathrm{~min}$ after injection of pentobarbitone. This decrease in latency was greater than the maximal decrease observed in the saline treated animals (two-way analysis of variance.

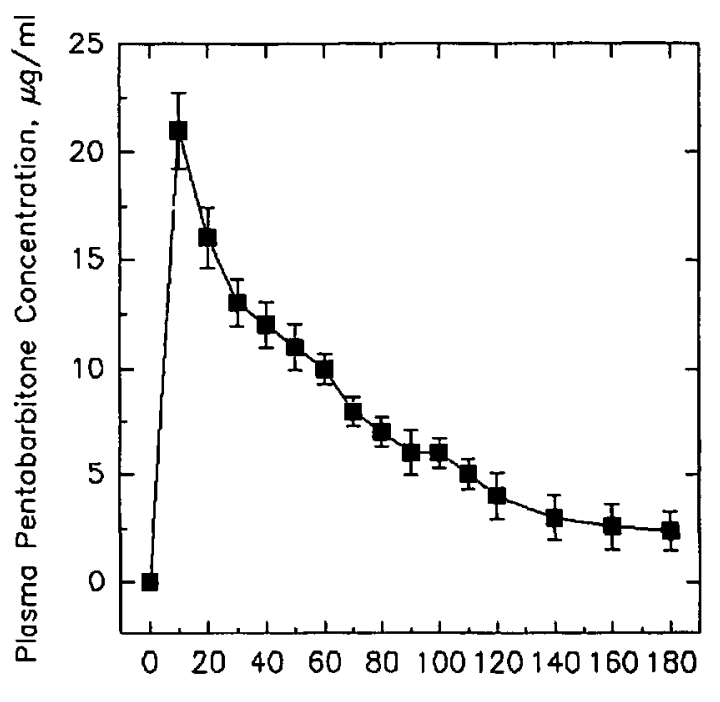

Time After Pentobarbitone Injection, minutes

8.

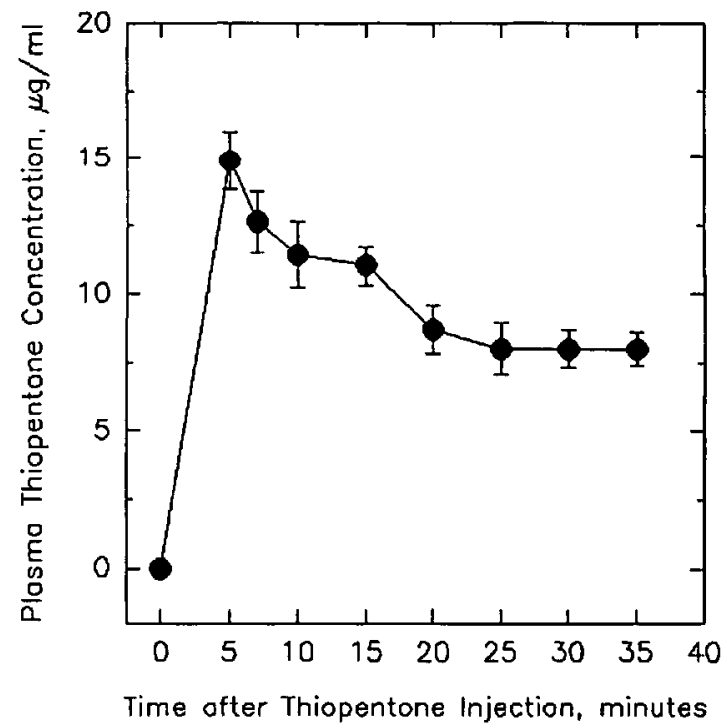

FIGURE I Plasma barbiturate concentrations (mean values \pm SEM) after A. intraperitoneal injection of $30 \mathrm{mg}^{-1} \mathrm{~kg}^{-1}$ pentobarbitone (Protocol I - Pentobarbitone Emergence, 10 rats) and $B$. computer controlled infusion of thiopentone (Protocol II, Thiopentone Emergence, 7 rats).

$P=0.022$ ). In saline treated animals the control WL was $13.3(9.9-16.7)$ sec. The SMRT decreased $18 \%$ after pentobarbitone injection, reaching a statistically significant difference from control $40 \mathrm{~min}$ after injection $(P<0.001)$ (Figure 2B). In the control rats SMRT did not change [initial value - $186(173-199) \mathrm{g}$ ] 
A.

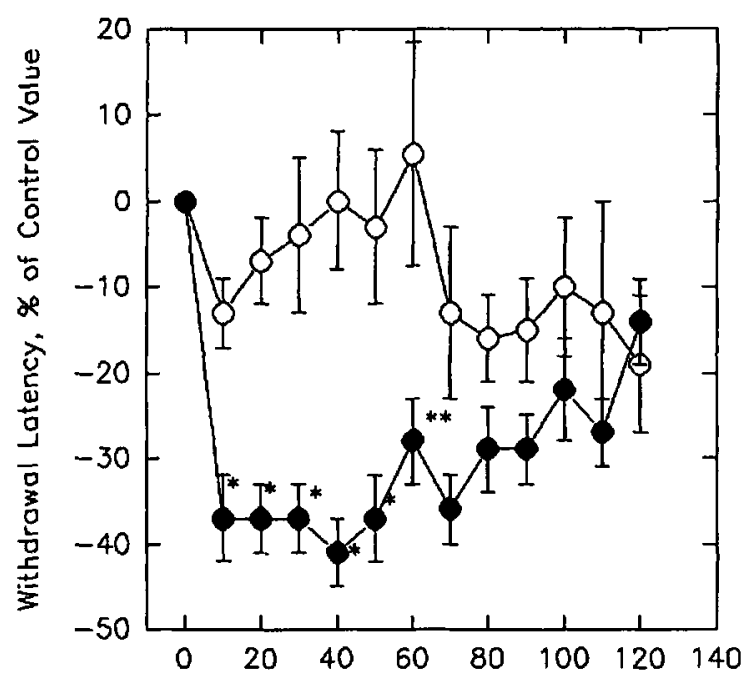

B.

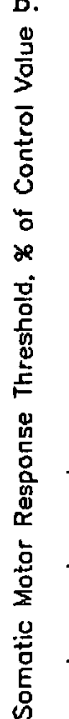

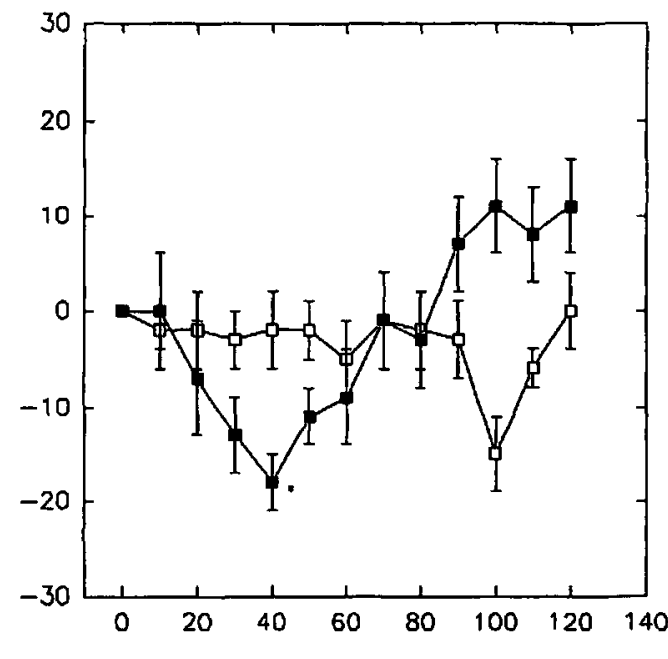

Time After Pentobarbitone Injection, minutes

FIGURE 2 Protocol I - Pentobarbitone Emergence A.

Withdrawal latency (WL), expressed as \% of control (pre-injection) values ( \pm SEM) after the injection of pentobarbitone $30 \mathrm{mg} \cdot \mathrm{kg}^{-1}$ (filled circles, 11 animals) or saline (empty circles, 8 animals). Asterisks signify difference from the value at the corresponding measurement time in the saline treated animals. ${ }^{*} P<0.01,{ }^{* *} P<0.05$

B. Somatic motor response threshold(SMRT), expressed as \% of control (pre-injection) values $( \pm$ SEM) after the injection of pentobarbitone $30 \mathrm{mg} \cdot \mathrm{kg}^{-1}$ (filled circles, 11 animals) or saline (empty circles, 8 animals). The asterisk signifies a difference from the value at the corresponding measurement time in the saline treated animals. ${ }^{*} P<0.001$.

Figure 3 shows the relationship between the plasma pentobarbitone concentrations $[\mathrm{Pb}]$ determined in partially restrained rats and withdrawal latency in the unrestrained animals. For the effect of pentobarbitone on WL, best fit was obtained with

Withdrawal latency $(\mathrm{sec})=16-0.98[\mathrm{~Pb}]+0.05[\mathrm{~Pb}]^{2}-0.001[\mathrm{~Pb}]^{3}$

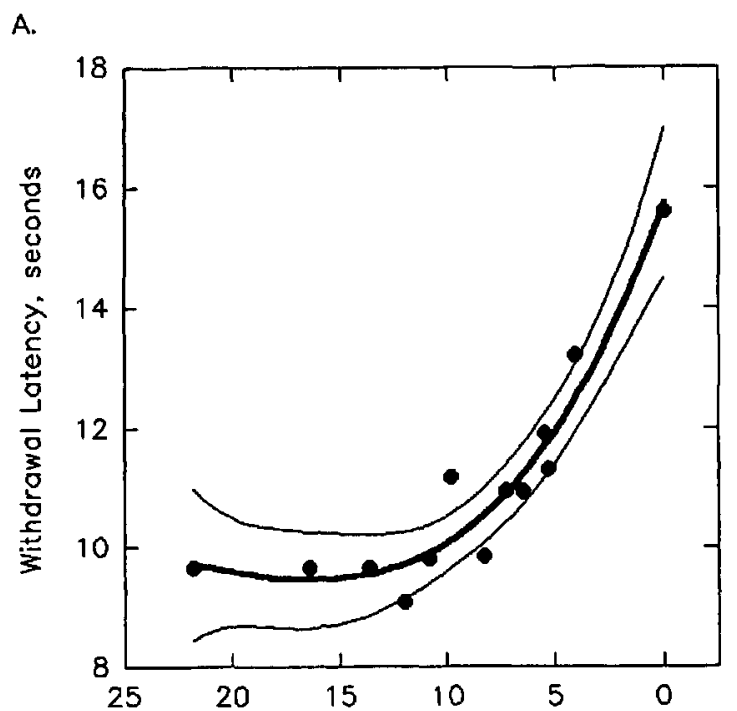

B.

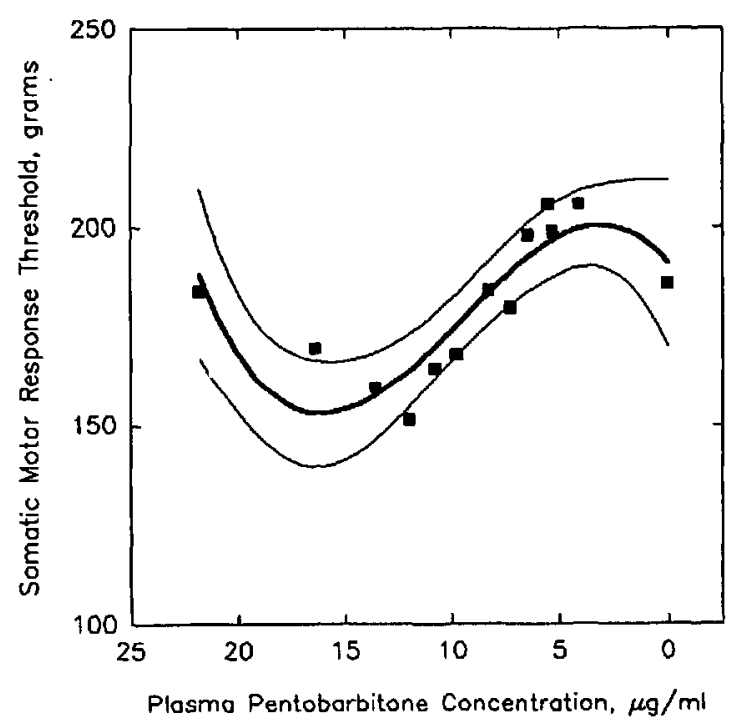

FIGURE 3 Protocol I - Pentobarbitone Emergence

Relationships between nocifensive reflexes and plasma pentobarbitone concentrations for withdrawal latency (WL) from a radiant thermal stimulus (A.) and for somatic motor response to tail pressure(SMRT) (B.) The heavy lines represent the best fit polynomial regression relationships $(P<0.001$ for $W L, P=0.003$ for SMRT), the finer lines represent the $95 \%$ confidence intervals for these relationships.

where $[\mathrm{Pb}]$ represents the plasma pentobarbitone concentration (analysis of variance $\mathrm{F}=36.71, \mathrm{DF}=12$, $P<0.001$ )

For SMRT, the best fit was obtained with $\operatorname{SMRT}(\mathrm{g})=191.3+6.34[\mathrm{~Pb}]-1.23[\mathrm{~Pb}]^{2}+0.043[\mathrm{~Pb}]^{3}$

(Figure $4 \mathrm{~B}$, analysis of variance $\mathrm{F}=10.66, \mathrm{DF}=12, \mathrm{P}=0.003$ ). 
TABLE II Effects of pentobarbitone injection on behavioral variables.

\begin{tabular}{|c|c|c|c|c|c|c|}
\hline \multirow[t]{2}{*}{ Time (min) } & \multicolumn{4}{|c|}{ Sedation Score } & \multicolumn{2}{|c|}{ Presence of Behaviour } \\
\hline & 0 & 1 & 2 & 3 & Paw Licking & Righting Reflex \\
\hline$\overline{0}$ & 11 & 0 & 0 & 0 & 6 & 11 \\
\hline 10 & 0 & 0 & 0 & 11 & 0 & 4 \\
\hline 20 & 0 & 0 & 3 & 8 & 0 & 5 \\
\hline 30 & 0 & 1 & 3 & 7 & 0 & 10 \\
\hline 40 & 0 & 3 & 7 & 0 & 0 & 11 \\
\hline 50 & 0 & 4 & 7 & 0 & 0 & 11 \\
\hline 60 & 1 & 10 & 0 & 0 & 0 & 11 \\
\hline 70 & 1 & 10 & 0 & 0 & 0 & 11 \\
\hline 80 & 6 & 5 & 0 & 0 & 1 & 11 \\
\hline 90 & 9 & 2 & 0 & 0 & 2 & 11 \\
\hline 100 & 10 & 1 & 0 & 0 & 4 & 11 \\
\hline 110 & 11 & 0 & 0 & 0 & 4 & 11 \\
\hline 120 & 11 & 0 & 0 & 0 & 3 & 11 \\
\hline
\end{tabular}

Number of animals within each behavior category before and at 10 minute intervals after intraperitoneal injection of pentobarbitone, 30 $\mathrm{mg} \cdot \mathrm{kg}^{-1}$. Sedation was scored as : 0 - awake; 1 - drowsy, responds to light stimulation of head or vibrissae; 2 - very drowsy, responds to vigorous stimulation of head or vibrissae; 3 - unresponsive to head or vibrissal stimulation.

\section{Protocol II - Thiopentone Emergence}

Thiopentone reduced the SMRT by approximately $30 \%$ of pre-injection values $(P<0.001)$, and this reduction was maintained throughout the experimental period (Figure 4A). Similar to previous findings $s^{2,4}$ in the concentration range $0-20 \mu \mathrm{g} \cdot \mathrm{ml}^{-1}$, there was a linear relationship between normalized SMRT and plasma thiopentone concentration:

SMRT $(\%$ of control $)=100-2 \cdot$ plasma thiopentone concentration (Figure $4 \mathrm{~B}$, ANOVA F=34.9, $P<0.001$ ).

In the saline-treated rats SMRT increased by $0.4 \%$ of control values per minute $(P=0.003)$.

Peak responsiveness for tail withdrawal during emergence from anaesthesia (results of present study) was of similar magnitude and occurred at plasma thiopentone concentrations similar to those reported previously ${ }^{1,2,4}$ during induction (Table III).

\section{Protocol III - Thiopentone Influx-Efflux}

The plasma thiopentone-nocifensive effect relationship during infusion and redistribution of thiopentone is summarized in Figure 5B. Analysis of the degree of hysteresis between the influx and efflux limbs showed that at a constant level of nocifensive effect ( $n=5$, four measures on the efflux limb, one measure on the influx limb) the mean difference in plasma thiopentone concentration between the influx and efflux limbs was $4(2.3-5.7) \mu \mathrm{g} \cdot \mathrm{ml}^{-1}$ (paired t test, $P=$ 0.003 ) If we assume that the kinetics of influx and efflux are similar, the resultant error due to the nonsteady-state design of the infusion is estimated at +2 $(1.2-2.8) \mu \mathrm{g} \cdot \mathrm{ml}^{-1}$ thiopentone (nonsteady-state plasma concentration greater than pseudosteady-state concentration). Using a three compartment pharma-

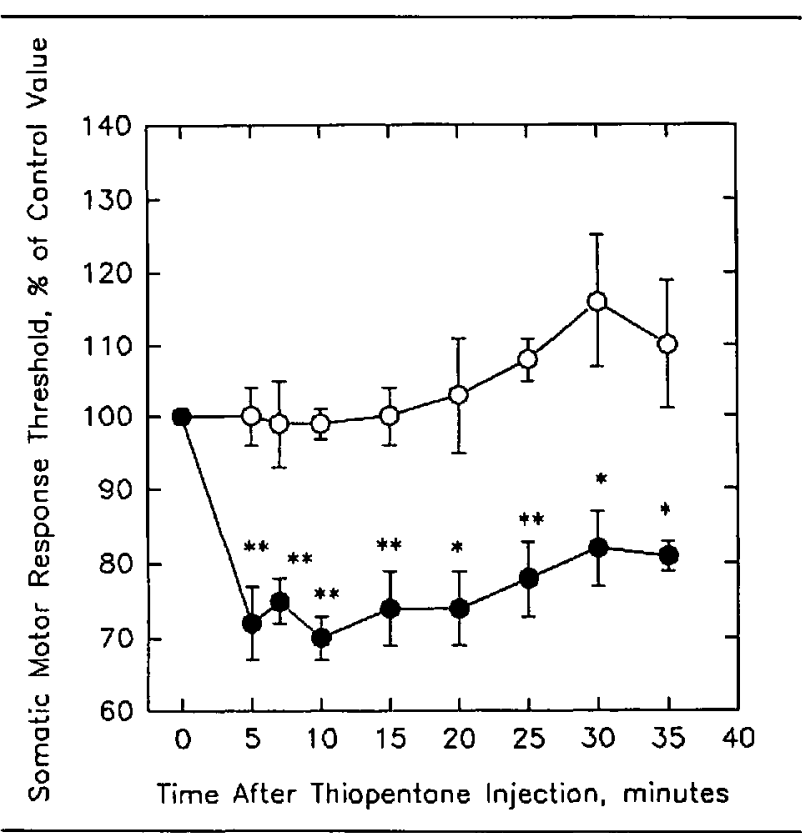

FIGURE 4 Protocol II - Thiopentone Emergence

A. Mean values \pm SEM of SMRT after a computer-controlled infusion programmed (STANPUMP) to achieve an effect site concentration of $20 \mu \mathrm{g} \cdot \mathrm{ml}^{-1}$. Filled circles represent thiopentone injected animals ( 7 rats); empty circles represent the 7 rats injected with saline. Comparisons made benween these two groups at the corresponding times - and $^{* *}$ signify $P<0.05$ and $P<0.01$ respectively. B. The relationship between SMRT and plasma thiopentone concentration in Protocol II. Within the thiopentone concentration range in this protocol, the relationship was linear $(P<0.001)$

cokinetic model for the rat (STANPUMP simulation programme $)^{13}$ to simulate conditions during the efflux limb of the present thiopentone emergence study, we estimated that the error was $+1.3(0.8-2.1)$ 
TABLE III Pharmacodynamic descriptors for SMR enhancement by thiopentone. Comparison of induction with emergence

\begin{tabular}{llll}
\hline \multicolumn{2}{c}{ Maxima, \% of Control } & \multicolumn{2}{c}{$C p_{\text {max }} \mu g \cdot \mathrm{ml}^{-1}$} \\
Induction & Emergence & Induction & Emergence \\
\hline $188(156-218)$ & $175(153-197)$ & $11(9-13)$ & $11(8.5-13.5)$ \\
$P$ & 0.510 & 0.931 & \\
\hline
\end{tabular}

Mean values ( $95 \% \mathrm{CI}) . \mathrm{Cp}_{\max }$, is the plasma thiopentone concentration observed at the time of maximal enhancement of the somatic motor response (SMR) to tail pressure. Data for induction were obtained from previous studies ${ }^{1,2,4}$ (14 rats). Data for emergence are from Protocol II (7 rats). $P$ is the significance level for an unpaired Student's $t$ test. Power of tests to detect a 30\% difference was $0.05(=0.05)$.

$\mu \mathrm{g} \cdot \mathrm{ml}^{-1}$. This model assumes an effect site rate constant of $0.58 \cdot \mathrm{min}^{-1}$. Thus, within the errors of measurement inherent in these studies, the kinetic behaviour of thiopentone at the nocifensive effect sites was similar (unpaired t test, $P=0.121$ ) to that seen at EEG effect sites. 5,16

\section{Discussion}

The results show that for low (subanaesthetic) doses of barbiturates, nocifensive reflex threshold measurements are modified by the barbiturates in a concentrationdependent, non-monotonic pattern. The SMRT was enhanced in a graded fashion to a similar degree during induction and emergence from anaesthesia (Table III). Direct comparison of thiopentone pharmacodynamics during influx and efflux showed counterclockwise hysteresis typical of effect site equilibration delay ${ }^{19}$ (Figure $5 B$ ). The magnitude of the equilibration delay observed experimentally was very similar to that predicted by the simulation model for the EEG effect site proposed by Stanski ${ }^{16}$ for pharmacodynamic modeling of the CNS effects of thiopentone. These results support our hypothesis that enhancement of nocifensive reflexes by subanaesthetic concentrations of barbiturates in the rat is a concentration-dependent, time-independent phenomenon. Further study comparing nocifensive reflexes with EEG measures of CNS effects would allow direct evaluation of the pharmacodynamics of thiopental for these two measures.

The results from Protocol I - Pentobarbitone Emergence - show enhancement of both nocifensive reflexes in unrestrained animals during emergence from anaesthesia. Therefore, we feel that it is unlikely that the enhancement of reflex responses observed previously in partially restrained animals ${ }^{1-4}$ can be explained by reversal of stress-induced analgesia. The results of the present study support previous findings ${ }^{1}$ that the influence of hindlimb partial restraint on SMRT (if present in this experimental model) is small, despite the theoretical possibility of immobilization stress and consequent analgesia. ${ }^{8}$

Reduction of nocifensive reflex thresholds was seen with both pressure and thermal stimulation. The experimental design in Protocol I attempted to provide a direct comparison of thermal and mechanical nociceptive effects of thiopentone. We compared these two forms of nociception because the putative mechanisms for tonic descending inhibition of nocifensive reflexes are proposed to differ for these two forms of noxious stimulation. ${ }^{9,20}$ The results show that for SMRT there was a biphasic response - enhancement of response at estimated pentobarbitone concentrations between 5 and $15 \mu \mathrm{g} \cdot \mathrm{ml}^{-1}$ and inhibition at pentobarbitone concentrations $>15 \mu \mathrm{g} \cdot \mathrm{ml}^{-1}$. These results are consistant with previous findings showing inhibition of the SMRT response at plasma pentobarabitone concentrations above $10 \mu \mathrm{g} \cdot \mathrm{ml}^{-1,2,4}$. The present study did not reveal any increase in WL, suggesting that the highest concentrations of pentobarbitone achieved were insufficient to produce inhibition of this response. Unfortunately, the present study did not compare the two stimuli on the same extremity (foot $v s$ tail), and did not use methods of comparable sensitivity and accuracy for assessing nocifensive reflexes. ${ }^{15}$ Consequently, we cannot determine from the present study whether these results are due to a physiological difference between the response to pressure and thermal stimulation or relate to the measurement techniques.

The mechanism(s) of nocifensive reflex enhancement by anaesthetic and hypnotic drugs is unknown. The nocifensive reflex is an elegant pathway for sensorimotor transformation in the mammalian spinal cord. $^{21}$ Changes in nocifensive reflex characteristics probably reflect primarily activity in spinal neurons rather than activity in ascending nociceptive pathways. ${ }^{22}$ Withdrawal of the rat hindlimb in response to a noxious stimulus results from the reflex activation and inhibition of a combination of muscles. ${ }^{22,23}$ Schouenborg and colleagues ${ }^{22}$ have proposed that the nocifensive reflex is functionally organized into numerous modules. Each module is composed of a cutaneous receptive field which is linked to specific "withdrawal" muscle by interneurons encoding spatial input-output features of the noxious stimulus. These neurons encoding reflex gain from the entire receptive 


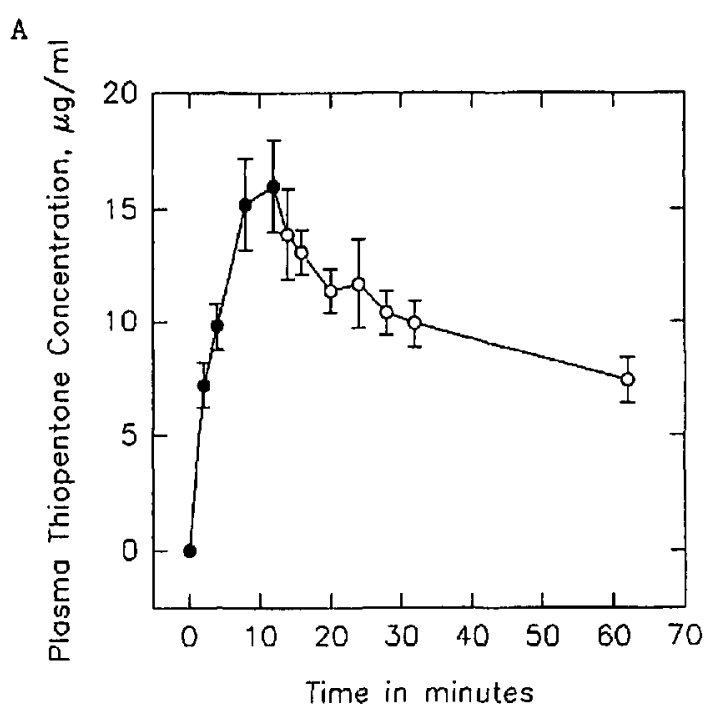

B

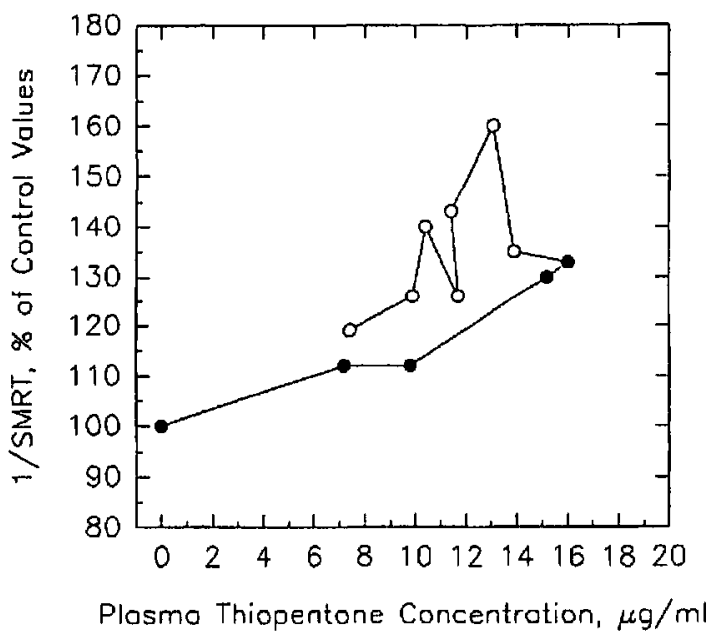

FIGURE 5 Protocol III - Thiopentone Influx-Efflux

A. Pharmacokinetics of thiopentone resulting from the infusion stratcgy for Protocol III. Symbols represent mean values \pm SEM for six rats observed during influx (filled circles) and efflux(empty circles) of thiopentone respectively.

B. Pharmacodynamic relationship between 1/SMRT and plasma thiopentone concentrations (filled circles influx, empty circles efflux). The figure shows counterclockwise hysteresis characteristic of equilibration delay during a nonsteady state infusion strategy. At constant values of $1 /$ SMRT, the mean difference in thiopentone concentration between the influx and efflux limbs of the infusion was $4(2.3-5.7) \mathrm{\mu g} \cdot \mathrm{ml}^{-1}(P=0.003)$.

field are proposed to project to alpha motoneurons in the ventral horn of the spinal cord to produce activation of a flexor muscle and inhibition of the corresponding extensor. Separate reflex pathways are proposed to exist for each of the non-antigravity muscles and, for each pathway, the cutaneous receptive

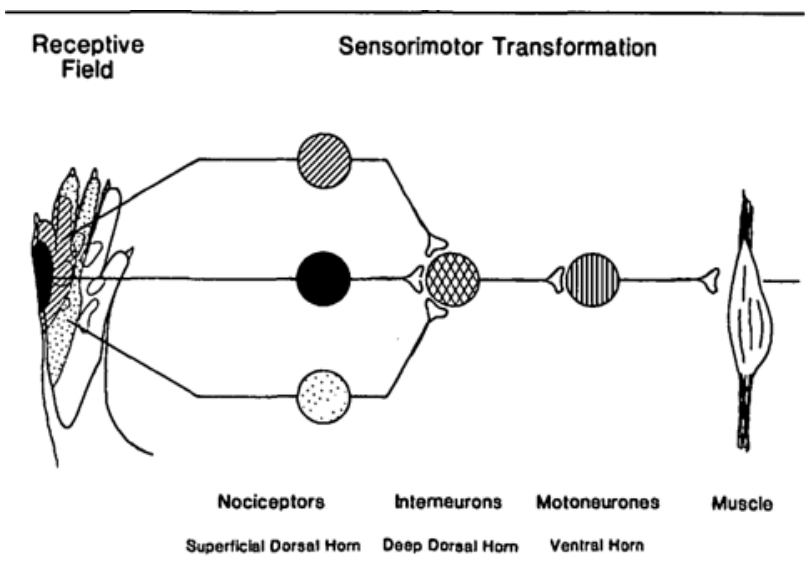

FIGURE 6 Model of the organization of a nocifensive reflex as proposed by Schoucnborg and colleagues. ${ }^{22}$ The figure shows the receptive and withdrawal fields for a single reflex module composed of nociceptors, interneurons encoding reflex gain, and motoneurons activating a single withdrawal muscle. The size of the withdrawal response produced by this module corresponds to the reflex gain encoded in the receptive field, indicated by the three levels of shading. Modified from the original ${ }^{22}$ with permission from the author.

field is located in a "mirror image" position to the limb surface most efficiently withdrawn by the muscle involved in that specific reflex arc (Figure 6). ${ }^{23}$

Reduction of WL or SMRT may therefore be due to many different effects of anaesthesia, including increased sensitivity of nociceptors to cutaneous stimulation, enlargement of receptive fields with or without increased convergence on reflex interneurons, modulation of activity in reflex interneurons, and increased sensitivity of motoneurons. Despite the diversity and complexity of the neural network, the results from the present and previous $^{1-4}$ studies suggest that nocifensive reflex thresholds offer a consistent measure of the spinal effects of anaesthetic drugs. More detailed study of the nocifensive reflex is warranted to examine how anaesthetics alter the specialized characteristics of the nociceptive signal (location, intensity, physical characteristics). This information may help us to understand the characteristics of the functional interaction of anaesthetics with nocifensive reflex pathways and sensorimotor transformation in the spinal cord.

\section{Acknowledgments}

These studies have been supported in part by the Burroughs Wellcome Inc. Canadian Research Award in Anaesthesia of the Canadian Anaesthetists' Society. The authors wish to thank Dr. S. Shafer and colleagues for the use of the STANPUMP program. 


\section{References}

1 Archer DP, Ewen A, Froelich J, Roth SH, Samanani N. Thiopentone induced enhancement of somatic motor responses to noxious stimulation: influence of $\mathrm{GABA}_{\mathrm{A}}$ receptor modulation. Can J Anaesth 1996; 43: 503-10.

2 Archer DP, Even A, Roth SH, Samanani N. Plasma, brain, and spinal cord concentrations of thiopental associated with hyperalgesia in the rat. Anesthesiology 1994; 80: 168-76.

3 Elwood $T$, Samanani $N$, Ewen A, Archer DP. Halothane causes hyperalgesia. Can J Anaesth 1995; 42: A7.

4 Ewen A, Archer DP, Samanani N, Roth SH. Hyperalgesia during sedation: effects of barbiturates and propofol in the rat. Can J Anaesth 1995; 42: 532-40.

5 Ebling WF, Danhof $M$, Stanski DR. Pharmacodynamic characterization of the electroencephalographic effects of thiopental in rats. J Pharmacokin Biopharm 1991; 19: 123-43.

6 Archer DP, Froelich J, McHugh M, Pappius HM. Local cerebral glucose utilization in stimulated rats sedated with thiopental. Anesthesiology 1995; 83: 160-8.

7 Soncrant TT, Holloway HW, Stipetic M, Rapoport SI. Cerebral glucose utilization in rats is not altered by hindlimb restraint or by femoral artery and vein cannulation. J Cereb Blood Flow Metab 1988; 8: 720-6.

8 Terman GW, Shavit $\Upsilon$, Lewis JW, Cannon JT, Liebeskind JC. Intrinsic mechanisms of pain inhibition: activation by stress. Science $1984 ; 226$ : 1270-7.

9 Meller ST, Gebbart GF. Nitric oxide (NO) and nociceptive processing in the spinal cord. Pain 1993; 52: 127-36.

10 Sandkiibler J, Gebhart GF. Characterization of inhibition of a spinal nociceptive reflex by stimulation medially and laterally in the midbrain and medulla in the pentobarbital-anesthetized rat. Brain Res 1984; 305: 67-76.

11 Gustafsson LL, Ebling WF, Osaki E, Stanski DR. Quantitation of depth of thiopental anesthesia in the rat. Anesthesiology 1996; 84: 415-27.

12 MacIver MB, Mandema JP, Stanski DR, Bland BH. Thiopental uncouples hippocampal and cortical synchronized electroencephalographic activity. Anesthesiology 1996; 84: 1411-24.

13 Gustafsson LL, Ebling WF, Osaki E, Harapat S, Stanski $D R$, Shafer SL. Plasma concentration clamping in the rat using a computer-controlled infusion pump. Pharm Res 1992; 9: 800-7.

14 Mark LC, Burns JJ, Campomanes CI, et al. The passage of thiopental into brain. J Pharmacol Exp Ther 1957; 119: 35-8.
15 Hargreaves $K$, Dubner $R$, Brown F, Flores $C$, Joris J. A new and sensitive method for measuring thermal nociception in cutaneous hyperalgesia. Pain 1988; 32: 77-88.

16 Stanski DR. Pharmacodynamic modeling of anesthetic EEG drug effects. Ann Rev Pharmacol Toxicol 1992; 32: 423-7.

17 Hull CJ, van Beem HBH, McLeod K, Sibbald A, Watson $M J$. A pharmcodynamic model for pancuronium. $\mathrm{Br}$ J Anaesth 1978; 50: 1113-23.

18 Fuseau $E$, Sheiner LB. Simultaneous modeling of pharmacokinetics and pharmacodynamics with a nonparametric pharmacodynamic model. Clin Pharmacol Ther 1984; 35: 733-41.

19 Holford NHG, Sheiner LB. Understanding the doseeffect relationship: clinical application of pharmacokinetic-pharmacodynamic models. Clin Pharmacokin $1981 ; 6: 429-53$.

20 Zhuo M, Meller ST, Gebhart GF. Endogenous nitric oxide is required for tonic cholinergic inhibition of spinal mechanical transmission. Pain 1993; 54: 71-8.

21 Schouenborg $J$, Weng $H$-R. Sensorimotor transformation in a spinal motor system. Exp Brain Res 1994; 100: $170-4$.

22 Schouenborg J, Weng $H-R$, Kalliomäki J, Holmberg $H$. A survery of spinal dorsal horn neurones encoding the spatial organization of withdrawal reflexes in the rat. Exp Brain Res 1995; 106: 19-27.

23 Schouenborg J, Kalliomäki J. Functional organization of the nociceptive withdrawal reflexes I. Activation of hindlimb muscles in the rat. Exp Brain Res 1990; 83: $67-78$. 